\title{
Microcomputer measurement and analysis of newborn sucking
}

\author{
D. C. MARTIN \\ University of Washington, Seattle, Washington \\ D. BORG-BREEN \\ National Oceanic and Atmospheric Administration, Seattle, Washington \\ and \\ J. C. MARTIN and A. P. STREISSGUTH \\ University of Washington, Seattle, Washington
}

\begin{abstract}
An on-line Basic computer program with on-line monitor prompts and read-out collects, stores, and digitizes pressure and latency of sucking responses for later analyses. The program and analog equipment are described, and approximate costs are noted.
\end{abstract}

A defective sucking response is one of the earliest and most reliable indicators of neurological distress in the newborn human (Cowett, Lipsitt, Vohr, \& Oh, 1978); sucking pressure, latency, and frequency may all be negatively affected (Kron, Stein, \& Goddard, 1963; D. C. Martin, J. C. Martin, \& Streissguth, 1979). The inability to ingest sufficient nutrients may compromise an already weakened system in high-risk infants, such as those born prematurely (Cowett et al., 1978) and those who are exposed prenatally to drugs (Kron, Litt, Phoenix, \& Finnegan, 1976; Stock, Streissguth, \& D. C. Martin, 1985). It is important to identify a sucking problem early, since failure to thrive can predict later neurobehavioral deficits (Lipsitt, 1979).

In 1979, we published a sucking conditioning study of infants born to smokers and social drinkers, in which we utilized then state-of-the-art equipment: preamplifiers and differential pressure transducers, transducer read-out equipment for signal amplification, and instrumentation tape-recorders. The schedule was programmed with an LVB Logic Box, and the signals were digitized and laboriously analyzed on a PDP-11 minicomputer (J. C. Martin, D. C. Martin, Lund, \& Streissguth, 1977). Today, however, microcomputer technology allows the entire instrumentation and computer system that we described in our previous study to be replaced with a small portable package. Yet when we recently attempted to replace the old system, we were unable to find readily available hardware or software, so we had to design our own.

This research was supported by NIDA/ADAMHA Grant, DA05365 to A. P. Streissguth. Reprints may be obtained from D. C. Martin, Department of Biostatistics, SC-32, University of Washington, Seattle, WA 98195 .

\section{Hardware Design}

Three NEC Powermate Port/40, "lunch-box" microcomputers were selected for data acquisition and analysis. Two of them had 20-MB disks; the third unit had a 40-MB disk, which was used for software development. A DAS-8 analog-to-digital conversion card (MetraByte, Taunton, MA) was installed in each machine. A Calex 160-MK bridge sensor (Calex, Pleasant Hill, CA) amplifier interface was connected to a DTX ${ }^{\mathrm{tm}}$ (TNF-R) disposable pressure transducer (Spectramed, Oxnard, CA), which was connected to 6 in. of flexible $.5-\mathrm{cm}$-diameter tubing, with a Luer fitting (Upchurch Scientific Inc., Oak Harbor, WA). The orthopedic type of nipple did not form a tight seal with the tubing, so a standard nipple was used (Evenflo). An opening sized for either a newborn or a prematurely born infant works equally well. Nipples were discarded after each use, and the tubing and pressure transducer were sterilized with gas for repeated use. An $\mathrm{X}$-Caliber calibrator (Spectramed) was used for calibration prior to the start of Trial 1. One entire package was assembled at a cost of $\$ 4,325.00$ (excluding disposable

Table 1

Digitized Printout of Sucking Session for One Baby

\begin{tabular}{|c|c|c|c|c|}
\hline & Avgpressure: 00.2 & \#Sucks:5 & & \\
\hline Trial:02 & Avgpressure:02.5 & \#Sucks:1 & Latency: 18.62 & $07: 11$ \\
\hline Trial:03 & Avgpressure:03.5 & \#Sucks:5 & Latency: 00.50 & $07: 12$ \\
\hline Trial:04 & Avgpressure:01.6 & \#Sucks:2 & Latency: 13.55 & $07: 12$ \\
\hline Trial:05 & Avgpressure:01.5 & \#Sucks:0 & Latency: 20.05 & $07: 12$ \\
\hline Trial:06 & Avgpressure: 12.6 & \#Sucks: 15 & Latency: 12.89 & $07: 13$ \\
\hline Trial:07 & Avgpressure:01.2 & \#Sucks:0 & Latency:20.05 & 07:13 \\
\hline Trial:08 & Avgpressure: 27.5 & \#Sucks:36 & Latency:01.71 & $07: 15$ \\
\hline Trial:09 & Avgpressure: 26.9 & \#Sucks:29 & Latency: 00.83 & $07: 16$ \\
\hline Trial: 10 & Avgpressure: 21.6 & \#Sucks:25 & Latency:00.22 & $07: 17$ \\
\hline Trial:11 & Avgpressure:08.2 & \#Sucks: 12 & cy: 00.83 & $07: 18$ \\
\hline Trial: 12 & Avgpressure:06.6 & \#Sucks: 10 & Latency:00.94 & $07: 19$ \\
\hline Trial: 13 & Avgpressure:11.6 & \#Sucks: 14 & Latency:00.94 & $07: 20$ \\
\hline & Avgpressure: 17.4 & \#Sucks: 27 & Latency:01.87 & $07: 21$ \\
\hline Trial: 15 & Avgpressure:25.9 & \#Sucks:36 & Latency: 00.44 & 07:22 A. \\
\hline
\end{tabular}


items): NEC, $\$ 2600$; math coprocessor, $\$ 250$; calibrator, $\$ 500$; cable, $\$ 100$; bridge sensor, $\$ 215 ; 8$-channel analog input board, $\$ 560$; and Turbo BASIC driver, $\$ 100$. The current cost would be less. Laptop computers are now available that can accept the analog input board. They would be more convenient than the NEC Powermate.

\section{Procedure}

This apparatus was developed for newborns who were 1 day old. They were tested between feedings on a vari- ety of tasks, which had been chosen to assess neurological integrity. The sucking task consisted of 1520 -sec trials with 5-sec intertrial intervals, for a total test period of 6-7 min. At the start of the trial, the nurse placed the nonnutritive nipple in the infant's mouth, after which the technician pressed the Enter key on the computer. The computer then began the count of elapsed time, which was displayed in seconds on the screen. At the end of the trial, the nurse removed the nipple from the baby's mouth, counted $5 \mathrm{sec}$, and reinserted the nipple; Trial 2 then be-

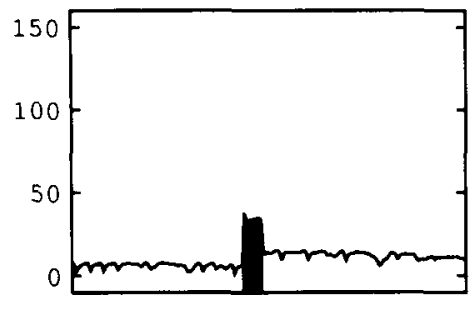

1
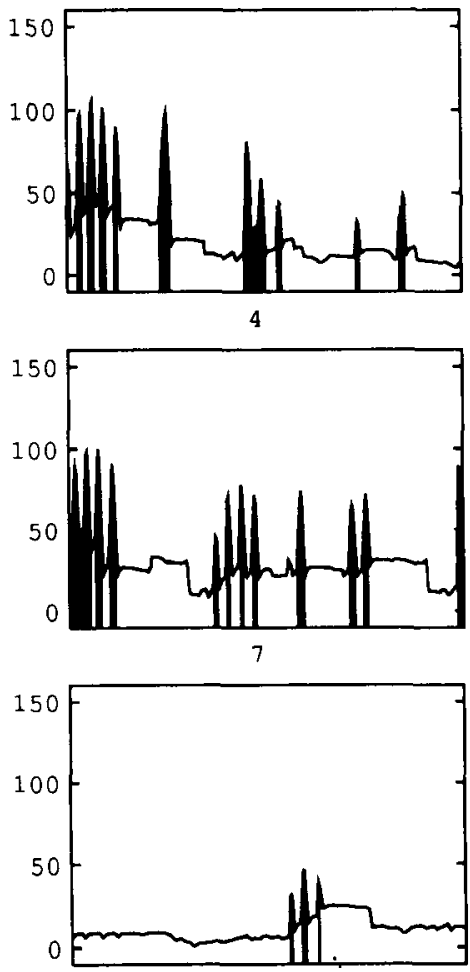

10

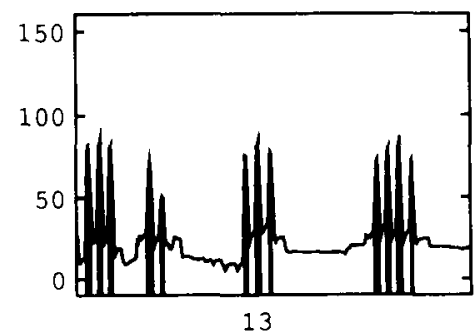

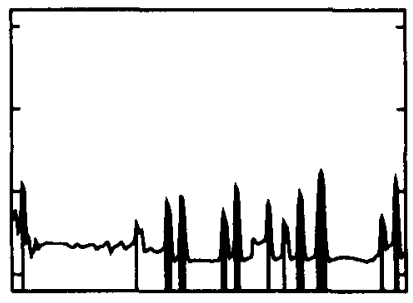

2
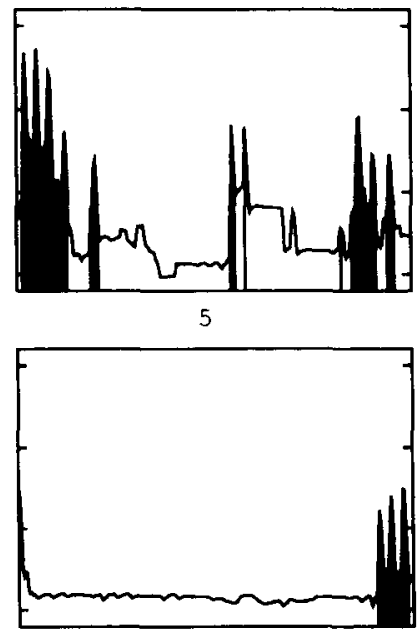

8

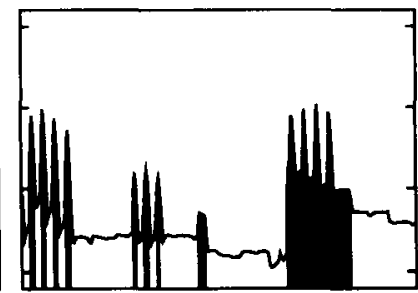

11

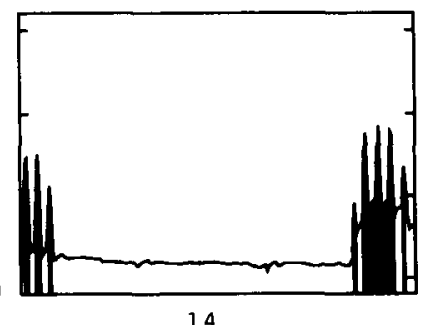

14

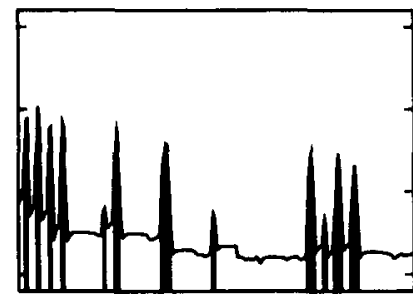

3
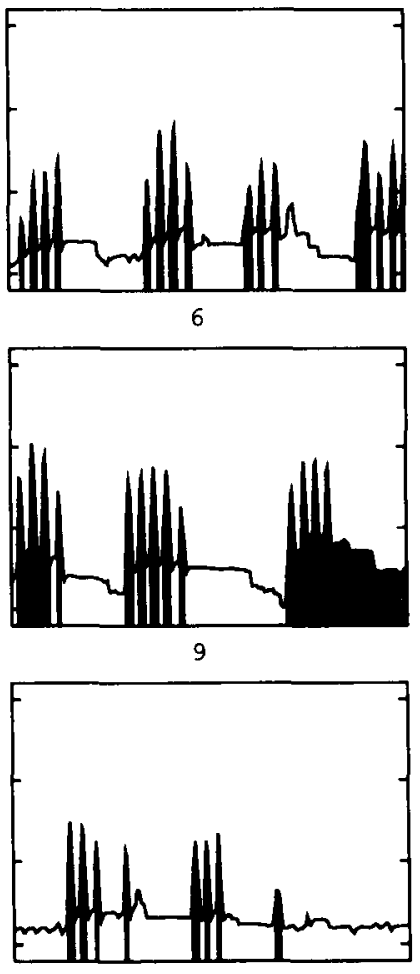

12

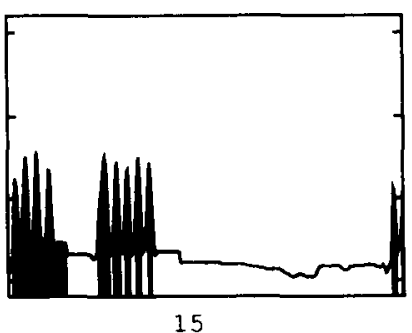

Figure 1. Analog record of sucking session for one baby. Each numbered block represents one 20-sec trial. The horizontal line is the floating baseline; the vertical excursions are sucks. The horizontal axis represents time; the vertical axis represents pressure in millimeters of mercury. 
gan. Sucking itself was displayed on the screen in real time as a moving graph that served as a visual monitor.

\section{Software Design}

The program is written in TurboBasic (Borland, Scott's Valley, CA). ${ }^{1}$ MetraByte LOAD-DAS-8 and DAS-8 subroutines carry out the analog-to-digital conversion. The graphics routines are device-independent but use a VGA (videographics adaptor) emulation mode.

Table 1 is a typical digitized printout of a sucking session and Figure 1 is an analog printout. The two are not records of the same infant.

\section{Dependent Measures}

The following measurements are taken: (1) the average pressure in millimeters of mercury for each of the 15 trials, (2) the number of sucking episodes as defined by a floating baseline (see below), and (3) the latency in seconds to the first suck for each of the 15 trials.

\section{Floating Baseline}

A shifting baseline to define an individual suck is mandatory, since some infants do not completely release the pressure between sucks but maintain it and raise the pressure for the next episode.

The floating baseline, $b_{t}$, is computed when in the nonsucking state by $b_{t+1}=0.9 b_{t}+0.1 p_{t}$, where $p_{t}$ is the pressure at time point $\propto$. A suck state is assumed to begin once $p_{t+1}$ exceeded $b_{t}$ by $10 \mathrm{~mm}$ and is terminated when $p_{t}$ decreases below the threshold that starts the suck (the baseline at the beginning of the suck plus $10 \mathrm{~mm}$ ). Once the suck state is terminated, the floating baseline update is started again. See subroutine TESTSUCK (Appen$\operatorname{dix}$ A) for the algorithm.

\section{Program Description}

1. The baby number and related data entry are specific to this study and not included.

2. The program requests a $-50 \mathrm{~mm}$ and a $0-\mathrm{mm}$ calibration pressure. The calibration is displayed graphically and can be repeated until the correct pressure is achieved.

3. The program takes 15 trials of $20 \mathrm{sec}$ at 18 samples per second. This display is useful for verification of correct operation. The sucks and timing are analyzed in real time. The display is switched to reverse video at the end of the trial. This is noticeable even when the examiner is not looking directly at the display.

4. All of the raw values and the derived data are written to disk at the end of each trial.

The key subroutines-TESTSUCK, CALIBRATE, and SUCK-are included in Appendices A, B, and C. SUCK samples the pressure data, plots data, and stores data on disk. CALIBRATE establishes conversion to millimeters of pressure from analog to digital units. TESTSUCK determines whether a suck has occurred.

\section{Program Availability}

These subroutines are available by mail. Send a doublesided, double-density 3.5- or 5.25-in. diskette and a re- usable diskette mailer to Donald C. Martin, Department of Biostatistics, SC-32, University of Washington, Seattle, WA 98195.

\section{REFERENCES}

Cowett, R. M. , Lipsitt, L. P., Vohr, B., \& OH, W. (1978). Aberrations in sucking behavior of low-birthweight infants. Developmental Medicine \& Child Neurology, 20, 701-709.

Kron, R. E., Litt, M., Phoenix, M. D., Finnegan, L. P. (1976). Neonatal narcotic abstinence: Effects of pharmaco-therapeutic agents and maternal drug usage on nutritive sucking behavior. Journal of Pediatrics, 88, 637-641.

Kron, R. E., Stein, M., Goddard, K. E. (1963). A method of measuring sucking behavior of newborn infants. Psychosomatic Medicine, 25, 181-191.

LiPsITT, L.P. (1979). Critical conditions in infancy: A psychological perspective. American Psychologist, 34, 973-980.

Martin, D. C., Martin, J. C., Streissguth, A. P. (1979). Sucking frequency and amplitude in newborns as a function of maternal smoking and drinking. In V. M. Galanter (Ed.), Currents in alcoholism (Vol. 5, pp. 359-366). New York: Grune \& Stratton.

Martin, J. C., Martin, D. C., Lund, C. A., \& Streissguth, A. P. (1977). Maternal alcohol ingestion and cigarette smoking and their effects on newborn conditioning. Alcoholism: Clinical \& Experimental Research, 1, 243-247.

Stock, D. L., Streissguth, A. P., Martin, D. C. (1985). Neonatal sucking as an outcome variable: Comparison of quantitative and clinical assessments. Early Human Development, 10, 273-278.

\section{NOTE}

1. Borland's TurboBasic is now distributed as PowerBASIC through Spectra Publishing, 1030D East Duane Ave., Sunnyvale, CA 94086.

\section{Appendix A}

TESTSUCK

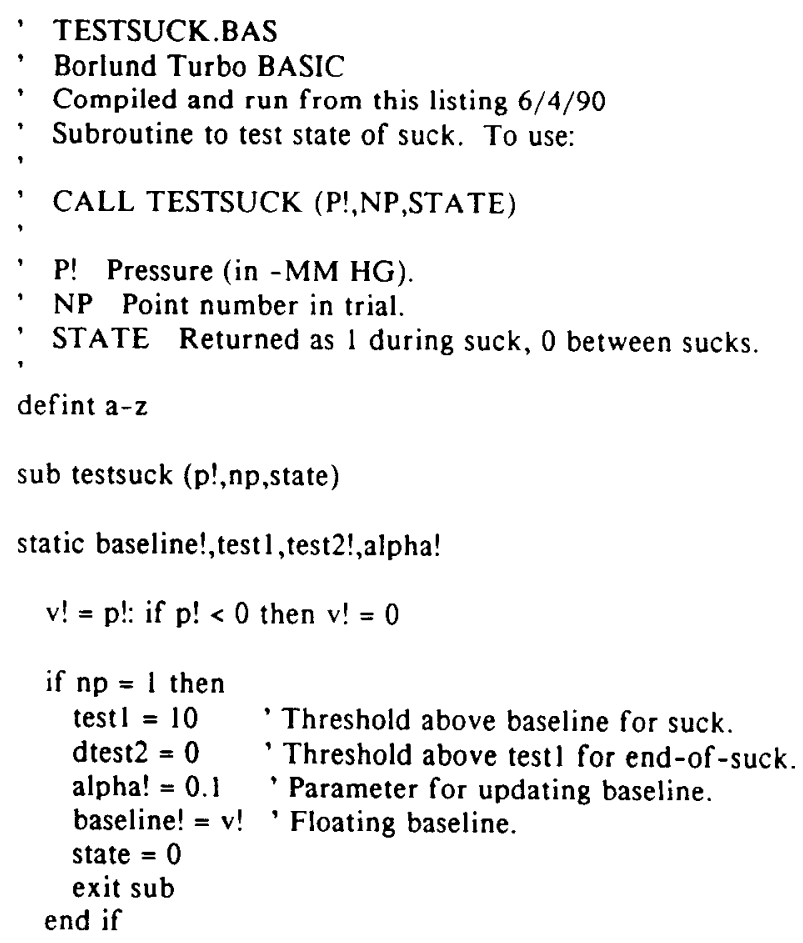

- Subroutine to test state of suck. To use:

' CALL TESTSUCK (P!,NP,STATE)

- P! Pressure (in -MM HG)

- NP Point number in trial.

- STATE Returned as 1 during suck, 0 between sucks.

defint a-z

sub testsuck (p!,np,state)

static baseline!,test 1, test 2 !,alpha!

$$
\begin{array}{ll}
v !=p !: \text { if } p !<0 \text { then } v !=0 \\
\begin{array}{ll}
\text { if } n p=1 \text { then } & \\
\text { test } 1=10 & \text {, Threshold above baseline for suck. } \\
\text { dtest } 2=0 & \text {, Threshold above test } 1 \text { for end-of -suck. } \\
\text { alpha! }=0.1 & \text {, Parameter for updating baseline. } \\
\text { baseline! }=v ! & \text { ' Floating baseline. } \\
\text { state }=0 & \\
\text { exit sub } &
\end{array} \\
\text { end if }
\end{array}
$$




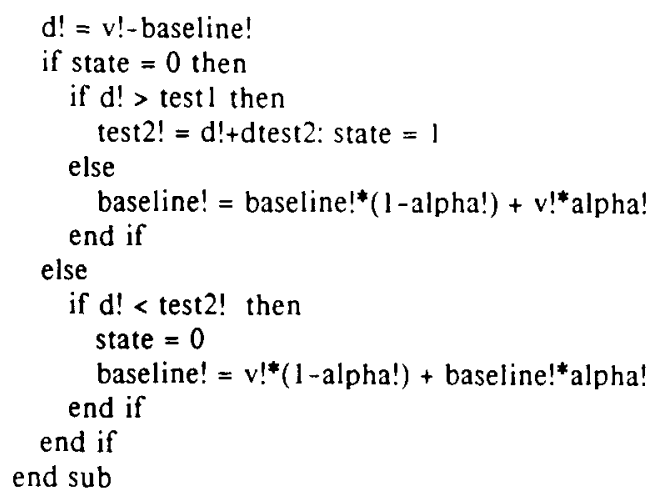

. DATA-SAMPLING ROUTINE DURING BABY SUCKING. by David Borg-Breen, modified by DCM $11 / 17 / 89$

DEFINT $A-Z$

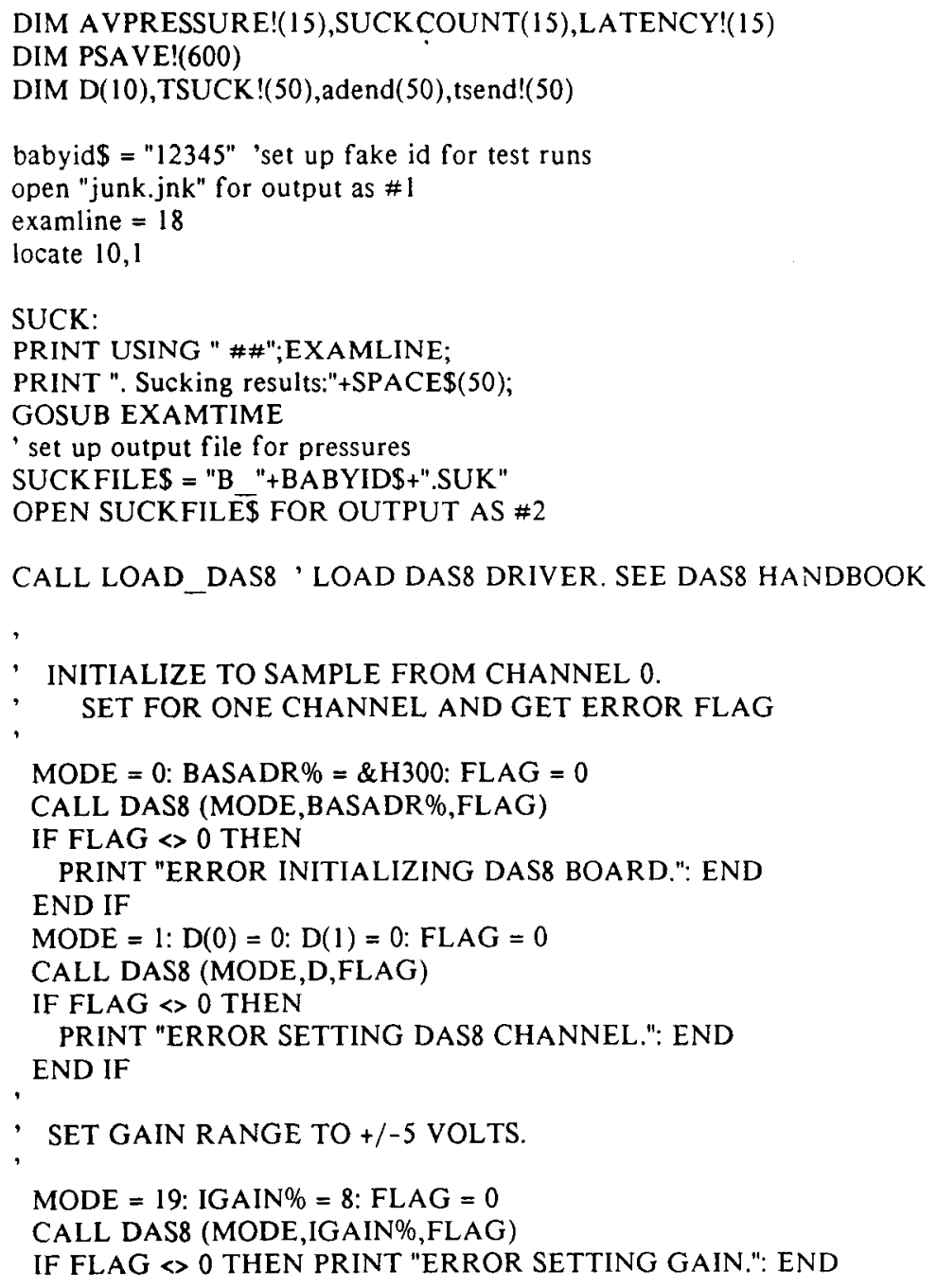


Appendix B (Continued)

VLOW! $=-5.0: \mathrm{VHI}=+5.0$

IADLOW $=-1200:$ IADHI $=300$

ADPLOTRANGE! = IADHI - IADLOW

SET UP PLOT.

$I X 0=20: \quad I X I=590$

$I Y 0=140: I Y 1=10$

SCREEN 2

LINE (IX0,IY0) - (IX0,IYI)

LINE (IXI,IY0) - (IXI,IYI)

LINE (IX0,IYO) - (IXI,IY0)

LINE (IX0,IY1) - (IXI,IYI)

YFACT! = (IY1-IYO)/ADPLOTRANGE!

GOSUB CALIBRATE

IF IADOMM = IAD50MM THEN IAD50MM = IAD0MM -100

$\mathrm{A} !=50.0 /(\mathrm{IAD} 50 \mathrm{MM}-\mathrm{IAD} 0 \mathrm{MM})$

$B !=-50.0 *$ IADOMM/(IAD50MM-IAD0MM)

FOR NTRIAL $=1$ TO 15

CLS

LINE (IX0,IY0) - (IX0,IYI)

LINE (IXI,IY0) - (IXI,IYI)

LINE (IXO,IY0) - (IXI,IYO)

LINE (IX0,IYI) - (IXI,IYI)

$I Y=I Y 0+(\text { IAD50MM-IADLOW })^{*} Y F A C T !$

FOR IX = IXO TO IXI STEP 6: PSET (IX,IY): NEXT IX

$I Y=I Y 0+(I A D O M M-I A D L O W)^{*} Y F A C T$ !

FOR IX = IXO TO IXI STEP 6: PSET (IX,IY): NEXT IX

LOCATE 23,5

MSG01S=" (or Q, then [ENTER] to abort sucking trials.)"

PRINT" "+MSG01\$;

LOCATE 21,9

PRINT "Press [ENTER] to begin trial";

PRINT USING " \#\#: ";NTRIAL;

INPUT ,RESP\$:

IF RESP\$ = "Q" OR RESPS = "q" THEN GOTO OUTSUCK

LOCATE 21,1: PRINT SPACE\$(60)

PRINT SPACE\$(60): PRINT SPACE\$(60)

TO! = TIMER

PT! = TIMER: WHILE PT! $<=$ T0!: PT! = TIMER: WEND

$\mathrm{T} !=\mathrm{PT} !$

NPOINT $=0$

WHILE T!-TO! $<=20.0$

$$
\begin{aligned}
& \text { NAVG }=0 \\
& \text { ADTOT } \&=0 \\
& \text { DO }
\end{aligned}
$$

'GET ONE SAMPLE POINT $(\mathrm{MODE}=4)$

MODE $=4: F L A G=0$

CALL DAS8 (MODE,IAD,FLAG)

IF FLAG $<0$ THEN PRINT "ERROR SAMPLING DATA."

$N A V G=N A V G+1$

ADTOT\& $=$ ADTOT\& $+I A D$

$T !=$ TIMER 


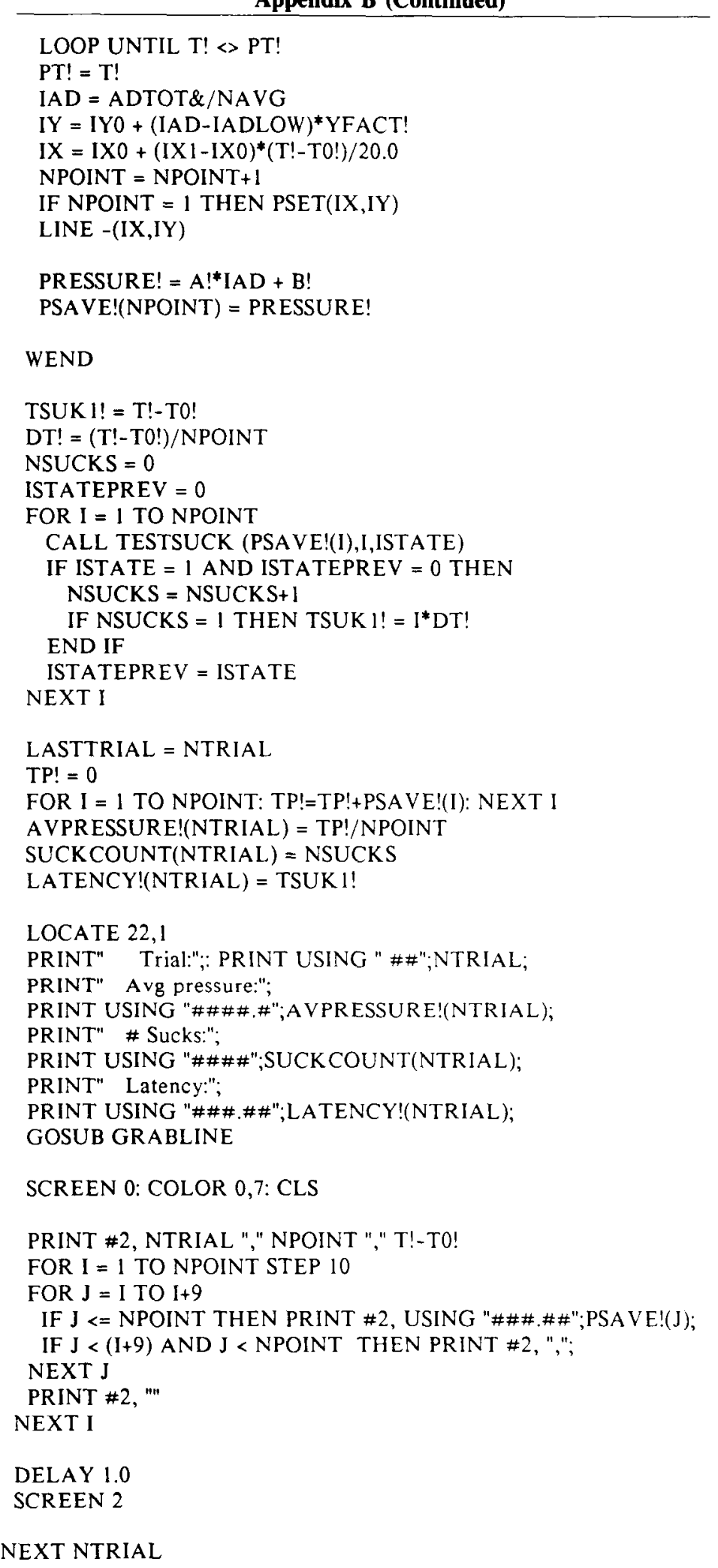


OUTSUCK:

PRINT \#2, 999 "," 0 "," 0.0

CLOSE \#2

SCREEN 0: COLOR 0,7: CLS

END

\section{Appendix C}

CALIBRATE

- Calibrate A/D data using $50 \mathrm{~mm}$ calibration level.

DIM D\%(10)

CALIBRATE:

TPLOT $!=5^{*} 60 \quad$ TOTAL PLOT TIME.

PLOTTIME0! = TIMER

NPT\& $=0$

ISTATE $=1$

IADOMM $=19999$

TRUE $=1$

LOCATE 25,4

PRINT "Calibration can be restarted by typing R";

WHILE TRUE

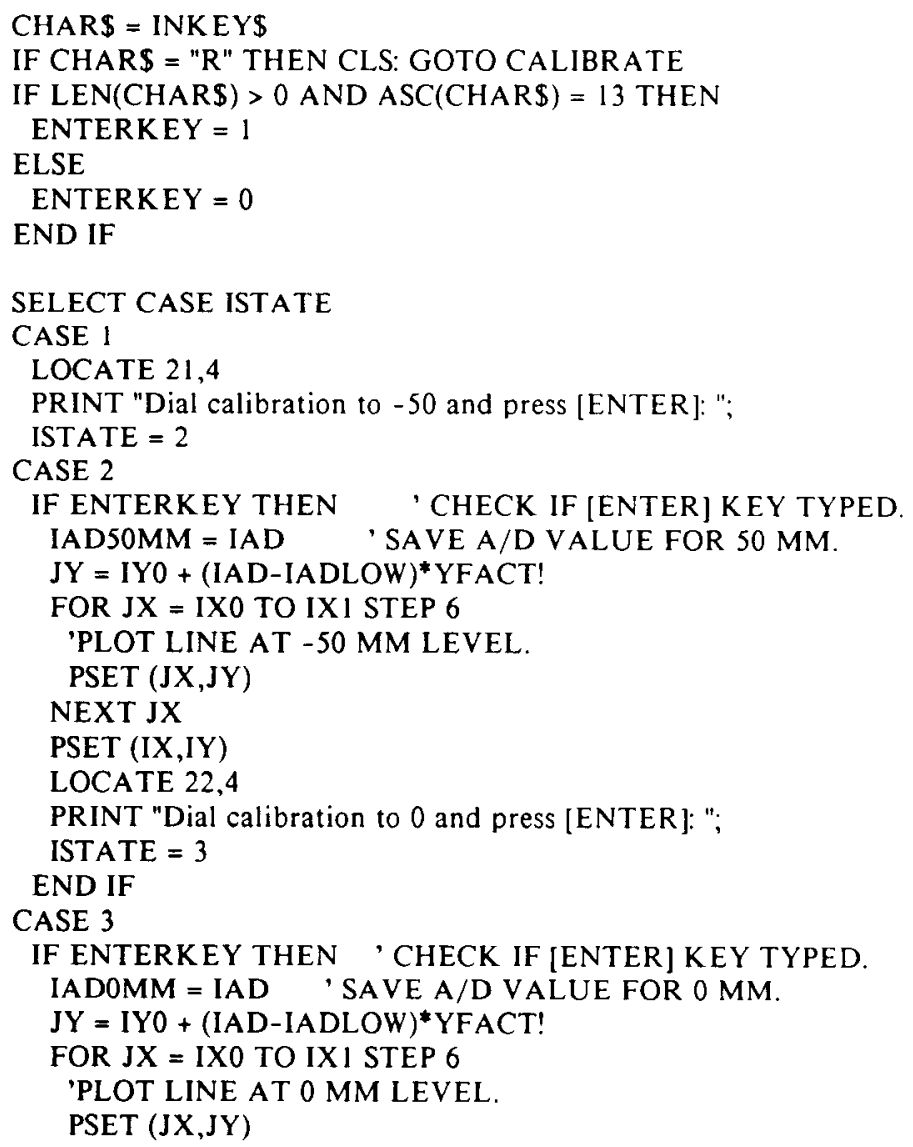


Appendix C (Continued)

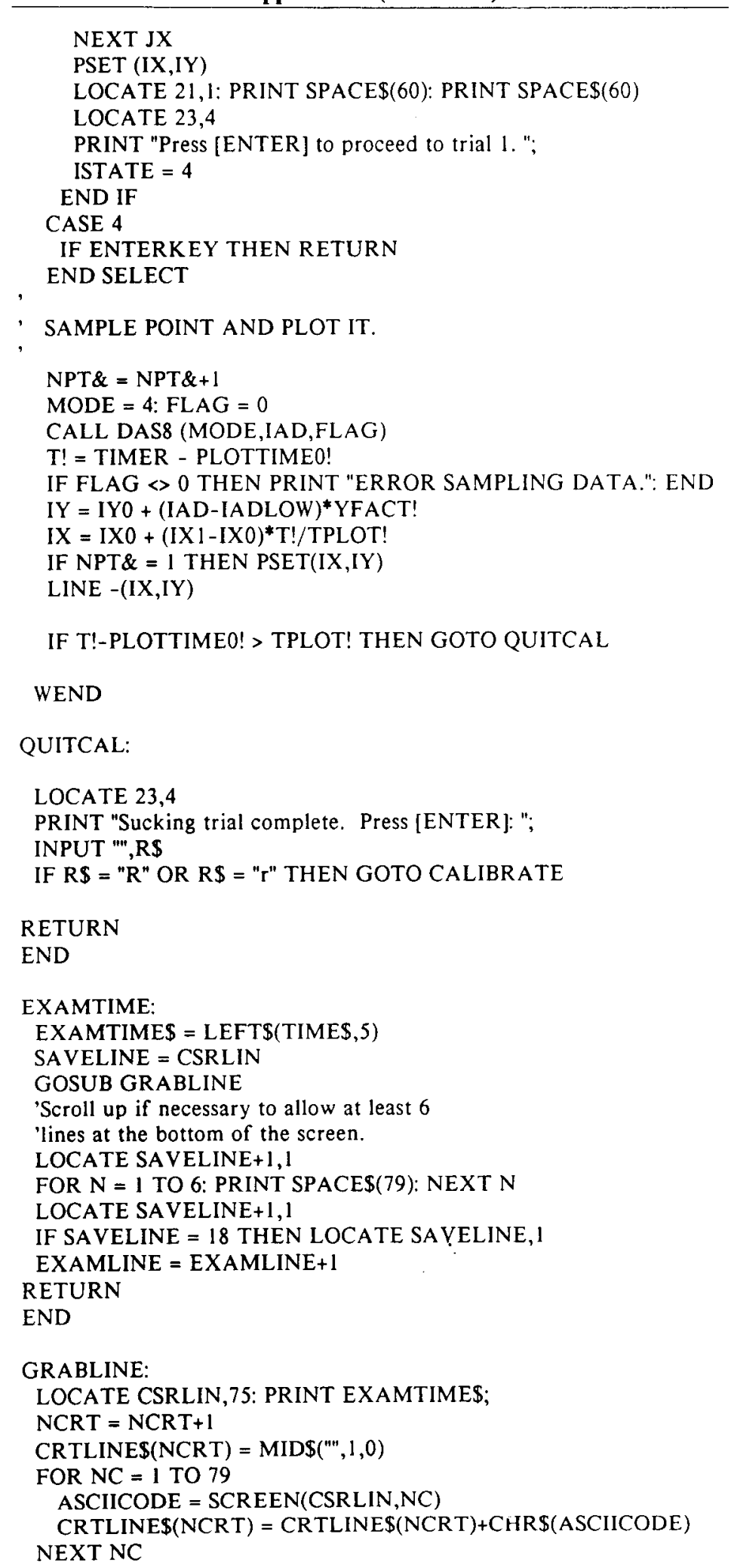


Appendix C (Continued)

PRINT \#1, CRTLINES(NCRT)

RETURN

END

SINCLUDE "DAS8.INC"

' Use if subroutines are in separate files

'\$INCLUDE "TESTSUCK.BAS"

'\$INCLUDE "CALIBRATE.BAS"

(Manuscript received January 22, 1990;

revision accepted for publication June 13, 1990.) 